\title{
Assessment of oral health status and treatment needs among people of Foklyan area, Dharan, Nepal
}

\author{
A. Singh ${ }^{1 *}\left(\mathbb{D}\right.$, A. Shrestha ${ }^{2} \mathbb{D}$, T. K. Bhagat ${ }^{2}$ and D. D. Baral ${ }^{3}$
}

\begin{abstract}
Background: Oral diseases are a major public health problem globally due to high prevalence and significant social impact. Foklyan is a peri urban area with people belonging to indigenous population of low socioeconomic status. This study was conducted to assess the oral health status and treatment needs among the people of Foklyan area, Dharan.

Methods: Cross-sectional house to house survey was conducted on 310 randomly selected participants. The participants were stratified into five age groups as per WHO Basic Oral Health Survey Methods 1997 and further categorized by gender. WHO Oral Health Assessment form 1997, WHO oral health assessment questionnaire for adult/children 2013 and questionnaire for oral hygiene practice and cost as a treatment barrier were used. The examinations were done as per WHO standard guidelines.

Results: Most of the participants were from low socioeconomic background (71.3\%). About $40 \%$ of the participants deferred dental visit due to financial burden. Although $99 \%$ of the participants brushed their teeth, there was high caries experience (DMFT: $3.18 \pm 5.85$; dft: $2.40 \pm 2.65$ ). Mean sextant score for bleeding was 5.58 in 35-44 years age group and 5.61 in $65-74$ years age group. Tobacco consumption was seen in $70.9 \%$ of the adults. Prevalence of alcohol consumption was $58.8 \%$ among adult age groups.
\end{abstract}

Conclusion: The prevalence of dental caries, periodontal diseases, and prosthetic needs were more compared to national data. There is a need for oral health promotion in this area.

Keywords: Sub-urban population, Nepal, Oral diseases, Oral health assessment, WHO oral health survey

\section{Background}

Oral health is a standard of the oral and related tissues which enables an individual to eat, speak, and socialize without active disease, discomfort, or embarrassment and which contributes to general wellbeing [1]. Oral health is a critical but overlooked component of overall health and wellbeing among children and adults. Oral diseases have a significant impact on the health and wellbeing of an individual through pain, morbidity, mortality,

\footnotetext{
*Correspondence: dr.abanishsingh@gmail.com

${ }^{1}$ Narayani Hospital, Birgunj, Parsa, Nepal

Full list of author information is available at the end of the article
}

and the lost capacity to undertake school, social and economic activities.

In Nepal, ever since the commencement of National Oral Health policy in year 2004 A.D. there has been significant amount of dental problems identified but still at present the prevention and treatment of oral diseases is virtually unavailable to the rural and underprivileged population due to various educational, cultural and socioeconomic burdens [2]. The burden of oral disease due to associated pain and discomfort may result in loss of teeth, difficulty in eating, poor diet and consequently affect one's appearance, self-esteem, and quality of life. There is a greatly increased risk of the development of 
life-threatening sequelae to dental infections due to poor nutrition, chronic diseases and the lack of availability of oral health care. Socioeconomic status, occupation, and education are playing a major role in the maintenance of good oral health. The maximum burden of all diseases rests with the disadvantaged and socially marginalized [3].

Dental caries is considered a major public health problem globally due to its high prevalence and significant social impact. World Health Organization reports $60-90 \%$ of schoolchildren worldwide have experienced caries, with the disease being most prevalent in Asian and Latin American countries [4]. In Nepal, the caries prevalence is found to be $64 \%$ in urban area and $78 \%$ in rural population whereas approximately $31 \%$ of age group 35-44 years have a deep periodontal pocket [2]. The WHO oral health assessment form 1997 is universally accepted for collection of all the information needed for planning oral care services and thorough monitoring and re-planning of existing care services.

Little is known about oral health attitudes and behaviors of people from developing countries as compared with developed countries [5]. There are few pieces of literatures conducted on the assessment of oral health status, oral health behavior among such underprivileged population in Nepal. Dental caries, gingivitis and periodontitis are very common oral health problems of Nepalese population, and the severity is more in case of underprivileged indigenous population groups [2]. Nepal is a poor underdeveloped country in terms of availability and accessibility of resources. Foklyan is a peri urban area of Dharan Sub-metropolitan city with most of the people belonging to the indigenous population of low socioeconomic status [6]. Studies have shown that the oral health of such population is poor and their attitude and practice towards oral health hygiene is often neglected $[4,7]$. Hence, this study was conducted to assess the oral health status and treatment needs among the people of Foklyan area, Dharan.

\section{Methods}

\section{Study design and participants}

It was a community-based cross-sectional study. The study was conducted from January 2017 to December 2017 among people of Foklyan area, Dharan, Nepal. Ethical approval was obtained from the Institutional Review Committee, BPKIHS, Dharan (Ref. No.: 300/074/074IRC). Three hundred ten people were randomly selected. A stratified random sampling technique was used. The participants were stratified into five age groups as per WHO Basic Oral Health Survey Methods 1997 and further categorized by gender. Social mapping was done to select the houses fitting as per the sampling design.
Thirty-one male and thirty-one females, for each age group, were randomly selected via lottery method from the 410 households in Foklyan. (Fig. 1).

This study considered $(95 \% \mathrm{CI})$ to estimate the sample size. For this purpose, $60.3 \%$ prevalence of dental caries in eastern Nepal (p) was considered, and the calculated sample size was 256 [8]. To increase the sensitivity and validity, and considering $15 \%$ non-response and also to fit the study design sample size was increased to 310 . The study included people above 5 years of age regardless of their medical condition (except psychiatric illness), and those not willing to take part in the study were excluded.

\section{Survey instruments}

a WHO Oral Health Assessment form 1997: It is universally accepted and used recording methodology for oral health surveys. The form includes many sections, like, survey identification information, general information, extra-oral examination, TMJ assessment, oral mucosa, enamel opacities/hypoplasia, dental fluorosis, community periodontal index, loss of attachment, dentition ststus and treatment needs, prosthetic status/need, dentofacial anomalies, need for immediate care and referral [9].

b Questionnaire for oral hygiene practice and cost as a treatment barrier: These questions were formulated by the authors referring to various published literatures.

c WHO oral health questionnaire for children/ adult 2013: These questionnaires provide reliable information about oral health status and risk to oral health. There are separate sets of questionnaires for adult and children. Both questionnaires have been pilottested in range of countries across the world [10].

d Socioeconomic status: The Kuppuswamy's Socioeconomic Status scale includes education, occupation

5 strata (WHO basic Oral Health survey age groups 5 years, 12 years, 15 years, 35-44 years, and 65-74 years) were taken
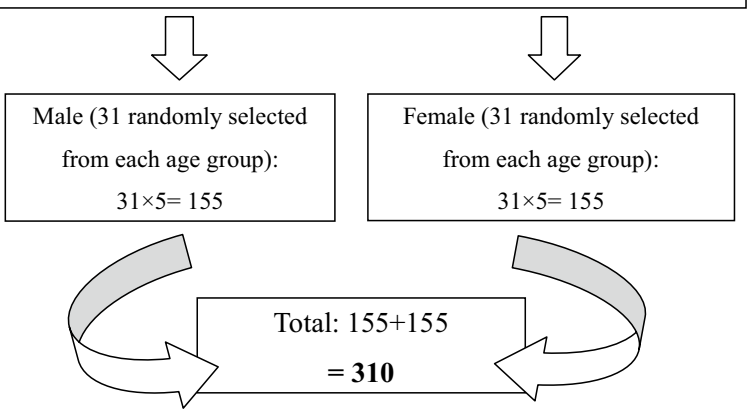

Fig. 1 Flow diagram of the participants 
of head of the family and income per month from all sources. It is categorized as upper class, upper middle class, lower middle class, upper lower class, and lower class. Kuppuswamy's Socioeconomic Status scale was calculated and classified as per the modifications done in the year 2009 using the current consumer price index for the year 2017 [11, 12]. Education and Occupation does not change as per time but the income varies with time. So, during modification of Kupuswamy Scale, the income was re-categorized based on current consumer price index of year 2017. To re-categorize the income, the current consumer price index was obtained online from Nepal Rastra Bank website [12] and the conversion factor was calculated (Conversion factor $=$ Consumer Price Index 2017 divided by Consumer Price Index 1976). The computed conversion factor was 26.7 (144.8/4.3). For simplicity, the classes were re-categorized as upper class, middle class and lower class [11].

\section{Survey procedure and outcome variables}

Interview of the participants were conducted during the home visits. In case of children, either of the parents gave the interview. Time taken for each interview was $15-20 \mathrm{~min}$. All the participants were examined at their houses by a single trained and calibrated examiner, under natural light using plane mouth mirror and WHO periodontal probe. Time taken for each examination was 5-10 min. The examinations were done as per WHO standard guidelines. Duplicate examinations were performed among 25 participants during the study to test the intra-examiner reliability. A pilot study was also conducted prior to the main study among 25 participants of similar community for training and calibration of the examiner along with the feasibility assessment of the study. Intra-examiner reproducibility was evaluated using Cohen Kappa statistics which showed excellent agreement $(K=0.912)$.

The primary outcomes measured were prevalence of dental caries, periodontal status and oral lesions along with oral hygiene behavior and cost as a barrier of participants. Data on socioeconomic status, enamel opacities, prosthetic needs, temporomandibular joint disorders, dentofacial anomalies and dental aesthetic index were also obtained. Dietary habits, tobacco consumption, alcohol consumption, pain and discomfort were also accessed.

\section{Data management and statistical measures}

Data obtained were entered in Microsoft Excel Sheet 2007 and statistical analysis was done in SPSS version 11.5 (SPSS, Inc., Chicago, IL, USA) software. Descriptive statistics including the mean and standard deviations were computed for DMFT/dmft. Frequency distribution among the study population was calculated. Frequency of oral lesions, prosthetic status and prosthetic needs, community periodontal index and loss of attachment, dentition status and treatment needs, dental aesthetic index were assessed. Mann-Whitney test was used to compare the mean DMFT/dft. A $p$ value $<0.05$ was considered statistically significant.

\section{Results}

The majority of the participants belonged to Dalit and Janajati category and about $12.3 \%$ belonged to BrahminChhetri category as classified by Nepal Demographic and Health Survey [13]. Most of the people belonged to the lower class $(71.3 \%)$ followed by the middle class $(1.6 \%)$ and about $27.1 \%$ did not respond to socioeconomic status. Majority (82.3\%) of the participants' self-perception regarding oral health status was good to average.

It was seen that $99 \%$ of the participants brushed their teeth. Most of the participants brushed once a day or 2-6 times a week and it was seen that majority of the participants brushed for 3-5 min. Most of them were found to be brushing with their tooth brush (85.8\%), followed by chewing stick (23.8\%). Very few were seen using thread and wooden toothpicks for cleaning (0.9\%). One participant was found using salt for cleaning teeth. Out of $99 \%$ who brushed their teeth, $89.1 \%$ used toothpaste. Table 1 (oral hygiene practices).

More than $60.0 \%$ of the males and females were having toothache/discomfort in the past 12 months but only $27.7 \%$ of males and $40.6 \%$ of females had a dental visit in their lifetime. Among the ones who had a dental visit, pain in the teeth was the main reason for the visit. Nearly $40 \%$ deferred dental visit due to financial problems. Out of those who visited the dentist, $60.6 \%$ of the participants were not able to afford the treatment and had to defer. Restorative treatments were deferred most. Table 2 (Dental problems and financial burden).

The tobacco exposure was high in the adult age groups. More than $70 \%$ belonging to the age group 35-44 years and 65-74 years were consuming tobacco in either form (smokeless or smoke form). The participants in 15 years age group were also consuming tobacco (43.5\%). The alcohol consumption in adults belonging to the age group $65-74$ years was $54.8 \%$.

The extra-oral status of all the participants was found normal. Overall, only six participants were having temporomandibular joint (TMJ) symptoms and on examination it was seen that $17(0.5 \%)$ had clicking. On examination for oral mucosal lesions, five of the participants had abscess, six had tobacco pouch keratosis, one had leukoplakia, and six had ulceration. The lesions were 
Table 1 Oral hygiene practices

\begin{tabular}{|c|c|c|c|c|c|c|}
\hline & 5 years & 12 years & 15 years & $35-44$ years & $65-74$ years & Total (\%) \\
\hline \multicolumn{7}{|l|}{ Brushing status } \\
\hline \multicolumn{7}{|l|}{ Male } \\
\hline Yes & 25 & 30 & 31 & 29 & 23 & $138(98.9)$ \\
\hline \multicolumn{7}{|l|}{ Female } \\
\hline Yes & 25 & 28 & 31 & 31 & 26 & $141(99.1)$ \\
\hline \multicolumn{7}{|c|}{ Duration of tooth brushing } \\
\hline $1-2 \min$ & 17 & 11 & 8 & 5 & 11 & $52(18.6)$ \\
\hline $2-3 \min$ & 8 & 20 & 20 & 11 & 10 & $69(24.7)$ \\
\hline More than 3 min & 25 & 27 & 34 & 44 & 28 & $158(56.7)$ \\
\hline \multicolumn{7}{|c|}{ Frequency of tooth brushing } \\
\hline Never & 14 & 10 & 5 & 2 & 12 & $43(13.8)$ \\
\hline Once a day & 1 & 1 & 3 & 31 & 16 & $52(16.7)$ \\
\hline Twice a day & 0 & 0 & 0 & 5 & 3 & $8(2.5)$ \\
\hline 1-3 times/week & 47 & 50 & 54 & 22 & 27 & $200(64.6)$ \\
\hline $1-3$ times/month & 0 & 1 & 0 & 2 & 4 & $7(2.4)$ \\
\hline \multicolumn{7}{|c|}{ Rinse of mouth after each meal } \\
\hline Always & 12 & 35 & 37 & 20 & 27 & $131(42.4)$ \\
\hline Sometimes & 44 & 25 & 25 & 42 & 35 & $171(54.9)$ \\
\hline Never & 6 & 2 & 0 & 0 & 0 & $8(2.7)$ \\
\hline \multicolumn{7}{|c|}{ Material used for tooth brushing } \\
\hline Toothbrush & 48 & 52 & 58 & 60 & 48 & $266(85.8)$ \\
\hline Chewing stick & 1 & 3 & 9 & 26 & 35 & $74(23.8)$ \\
\hline Toothpick & 0 & 0 & 0 & 1 & 1 & $2(0.6)$ \\
\hline Others & 0 & 0 & 0 & 1 & 0 & $1(0.3)$ \\
\hline
\end{tabular}

seen in lips, sulci, buccal mucosa, floor of the mouth, and alveolar ridges.

Enamel hypoplasia with diffuse opacity was found in only one participant of 11 years of age, whereas very mild dental fluorosis was seen in $4(1.3 \%)$ participants. When examined for prosthetic status, one had a bridge on the upper arch, and three participants had full removable denture on both upper and lower arches. Prosthetic needs were present in 23.6\% for the upper arch and 21.7\% for the lower arch. Pain and infection were seen in three participants and immediate referral was needed for one participant for abscess management. While assessing for Dental Aesthetic Index, elective treatment was indicated in $9.6 \%$ (category 2), highly desirable in 1.3\% (category 3 ) and mandatory in $5.8 \%$ of the participants.

The periodontal status was assessed using the Community Periodontal Index (CPI) in adult age groups. Sextant with pocket depth $4-5 \mathrm{~mm}$ was seen in $11.1 \%$ participants of age group 35-44 years and $24.5 \%$ of age group 65-74 years. Mean sextant was more for calculus and was most prevalent, with $82.3 \%$ in $35-44$ years age group and $74.5 \%$ in $65-74$ years age group. Loss of attachment of $0-3 \mathrm{~mm}$ was more commonly observed in 35-44 years age groups $(66.1 \%)$ and $4-5 \mathrm{~mm}$ in $65-74$ years age group
(43.6\%). Loss of attachment of $6-8 \mathrm{~mm}$ was seen in $30.9 \%$ of the $65-74$ years age group where as it was only in $6.4 \%$ in 35-44 years age group. Loss of attachment of 9-11 mm was also seen in six participants in both age groups. (Table 3).

Tooth decay was seen in $57.5 \%$ of people with permanent dentition, $28.4 \%$ of people with mixed dentition, and $65.1 \%$ of people with primary dentition. Missing due to caries was also more prevalent (34.4\%) in people with permanent dentition followed by missing due to any other reason. Most of the participants had unexposed roots $(71.5 \%)$ in permanent dentition.

One surface filling was required for $35.5 \%$ of the participants with permanent dentition, followed by $44.1 \%$ with primary dentition and $26.6 \%$ with mixed dentition. Extraction was indicated in $30.6 \%$ of the participants with permanent dentition, followed by $11.6 \%$ with primary dentition. Pulp care was needed mostly for participants with primary dentition (27.9\%) followed by $12.3 \%$ of permanent dentition. (Table 4).

Mean DMFT among males was $3.14 \pm 9.59$, and that among females was $3.23 \pm 5.76$. The difference was not statistically significant $(p=0.720)$. Also, mean $\mathrm{dft}$ among males and females was not statistically significant 
Table 2 Dental problems and financial burden

\begin{tabular}{|c|c|c|c|c|c|c|}
\hline & 5 years & 12 years & 15 years & $35-44$ years & $65-74$ years & Total (\%) \\
\hline \multicolumn{7}{|c|}{ Toothache/discomfort of participants in past 12 months } \\
\hline \multicolumn{7}{|l|}{ Male } \\
\hline Yes & 20 & 17 & 16 & 15 & 26 & $94(60.7)$ \\
\hline No & 8 & 11 & 10 & 7 & 4 & $40(25.8)$ \\
\hline Don't know & 3 & 3 & 5 & 9 & 1 & $21(13.5)$ \\
\hline \multicolumn{7}{|l|}{ Female } \\
\hline Yes & 13 & 17 & 19 & 24 & 25 & $98(63.4)$ \\
\hline No & 13 & 9 & 10 & 6 & 2 & $40(25.7)$ \\
\hline Don't know & 5 & 5 & 2 & 1 & 4 & $17(10.9)$ \\
\hline \multicolumn{7}{|c|}{ Dental visit of participants in their lifetime } \\
\hline \multicolumn{7}{|l|}{ Male } \\
\hline Yes & 1 & 8 & 13 & 12 & 9 & $43(22.7)$ \\
\hline \multicolumn{7}{|l|}{ Female } \\
\hline Yes & 7 & 10 & 18 & 14 & 14 & $63(40.6)$ \\
\hline \multicolumn{7}{|c|}{ Reason for dental visit } \\
\hline Pain & 4 & 14 & 23 & 14 & 16 & $71(66.9)$ \\
\hline Treatment & 0 & 2 & 1 & 10 & 4 & $17(16.0)$ \\
\hline Routine checkup & 4 & 2 & 7 & 2 & 3 & $18(16.1)$ \\
\hline \multicolumn{7}{|c|}{ Deferred dental visit due to financial burden } \\
\hline Male & 11 & 10 & 13 & 14 & 9 & $57(46.7)$ \\
\hline Female & 8 & 13 & 13 & 13 & 18 & $65(53.3)$ \\
\hline \multicolumn{7}{|c|}{ Deferred dental treatment due to financial burden } \\
\hline Male & 1 & 6 & 9 & 10 & 7 & $33(43.4)$ \\
\hline Female & 3 & 6 & 12 & 10 & 10 & $41(56.6)$ \\
\hline \multicolumn{7}{|c|}{ Types of treatment deferred } \\
\hline Restorative & 4 & 12 & 16 & 15 & 11 & $58(80.6)$ \\
\hline Prosthesis & 0 & 0 & 0 & 0 & 7 & $7(9.6)$ \\
\hline Extraction & 0 & 0 & 0 & 0 & 1 & $1(1.4)$ \\
\hline Scaling & 0 & 0 & 1 & 5 & 0 & $6(8.3)$ \\
\hline
\end{tabular}

( $p=0.400)$, the value being $2.64 \pm 2.86$ and $2.17 \pm 2.416$, respectively.

\section{Discussion}

This study assessed the oral health status and treatment needs of Foklyan area, Dharan, Nepal. The study showed that more than $90 \%$ of the study participants cleaned their teeth. Use of tooth brush was found in $85.8 \%$ of the study population which is similar to the study conducted by Thapa et al. [14].

The impact of oral diseases, especially in an under privileged indigenous population, affects their lives influencing eating, sleeping, and working along with social responsibilities. It was seen that majority of the study population perceived their oral health as good to average despite a high prevalence of plaque, calculus, and dental caries. This might be due to the poor knowledge regarding the understanding of oral conditions and diseases.
The findings were similar to the findings by Handa et al. [15] and Ghambhir et al. [16].

Toothache/discomfort was reported by more than $60 \%$ of the study population, but only $34.1 \%$ were found visiting the dentist for the problem. This can be well understood by the fact that most of the study population belonged to a lower socioeconomic class. Among the ones who visited, most were seen to visit due to pain in their teeth. Pain is the most common presentation of the dental patient visiting the dentist as reported in various studies $[17,18]$. Nepal is a poor country with most of the population belonging to the low socioeconomic status mostly indigenous population [13]. The dental visit was deferred by $39.3 \%$ of the study population due to financial burden.

Use of the tobacco products was seen in $43.5 \%$ of the 15 years age group (smokeless or smoke form) where as in adult age groups more than $70.6 \%$ were found consuming tobacco products. Almost $60.0 \%$ of the adults in the 
Table 3 Periodontal status (CPI)

Distribution of study population based on the specific CPI scores (as per highest scores obtained)

\begin{tabular}{lllll}
\hline Age group & Healthy $(\mathbf{H})$ & Bleeding $(\mathbf{B})$ & Calculus $(\mathbf{C})$ & Pocket 4-5 mm $\left(\mathbf{P}_{\mathbf{1}}\right)$ \\
\hline $35-44$ years $(n=62)$ & $2(3.3 \%)$ & $2(3.3 \%)$ & $51(82.3 \%)$ & $7(11.1 \%)$ \\
65-74 years $(n=55)$ & 0 & 0 & $41(74.5 \%)$ & $14(24.5 \%)$ \\
\hline
\end{tabular}

Distribution of mean sextant CPI scores in each age group

\begin{tabular}{lccccc}
\hline Age group & Healthy (0) & Bleeding (1) & Calculus (1+2+3+4) & $\begin{array}{l}\text { Pocket 4-5 mm } \\
(\mathbf{2}+\mathbf{3}+\mathbf{4})\end{array}$ & $\begin{array}{l}\text { Excluded } \\
\text { sextant } \\
(\mathbf{X})\end{array}$ \\
\hline 35-44 years $(n=62)$ & $0.4(25)$ & $5.58(346)$ & $5.40(335)$ & $0.22(14)$ & $0.01(1)$ \\
65-74 years $(n=55)$ & $0.05(3)$ & $5.61(309)$ & $5.5(307)$ & $0.34(19)$ & $0.23(14)$ \\
\hline
\end{tabular}

Distribution of study population based on loss of attachments (as per highest scores obtained)

\begin{tabular}{|c|c|c|c|c|c|}
\hline Age group & LOA 0-3 mm (0) & LOA 4-5 mm (1) & & LOA 6-8 mm (2) & LOA 9-11 mm (3) \\
\hline $35-44$ years $(n=62)$ & $41(66.1 \%)$ & $14(22.5 \%)$ & & $4(6.4 \%)$ & $3(4.8 \%)$ \\
\hline $65-74$ years $(n=55)$ & $11(20.0 \%)$ & $24(43.6 \%)$ & & $17(30.9 \%)$ & $3(5.4 \%)$ \\
\hline \multicolumn{6}{|c|}{ Distribution of mean sextant loss of attachments in each age group } \\
\hline Age group & $\begin{array}{l}\text { LOA } \\
0-3 \mathrm{~mm}(0)\end{array}$ & $\begin{array}{l}\text { LOA } \\
4-5 \mathrm{~mm}(1)\end{array}$ & $\begin{array}{l}\text { LOA } \\
6-8 \mathrm{~mm} \text { (2) }\end{array}$ & $\begin{array}{l}\text { LOA } \\
9-11 \mathrm{~mm} \text { (3) }\end{array}$ & $\begin{array}{l}\text { Excluded } \\
\text { sextant } \\
\text { (X) }\end{array}$ \\
\hline $35-44$ years $(n=62)$ & $5.25(326)$ & $0.45(28)$ & $0.23(14)$ & $0.07(4)$ & - \\
\hline $65-74$ years $(n=55)$ & $3.49(192)$ & $1.05(58)$ & $0.98(54)$ & $0.22(12)$ & $0.26(14)$ \\
\hline
\end{tabular}

Table 4 Dentition status and treatment needs

\begin{tabular}{|c|c|c|c|c|c|c|c|c|c|}
\hline \multicolumn{6}{|c|}{ Dentition status } & \multicolumn{4}{|c|}{ Treatment needs } \\
\hline \multirow{2}{*}{$\begin{array}{l}\text { Code } \\
\text { and criteria }{ }^{a}\end{array}$} & \multicolumn{3}{|c|}{ Crown status } & \multicolumn{2}{|l|}{ Root status } & \multirow[t]{2}{*}{ Scores $^{\mathbf{b}}$} & \multirow{2}{*}{$\begin{array}{l}\text { Primary } \\
\text { dentition }\end{array}$} & \multirow{2}{*}{$\begin{array}{l}\text { Mixed } \\
\text { dentition }\end{array}$} & \multirow{2}{*}{$\begin{array}{l}\text { Permanent } \\
\text { dentition }\end{array}$} \\
\hline & $\begin{array}{l}\text { Primary } \\
\text { dentition }\end{array}$ & $\begin{array}{l}\text { Mixed } \\
\text { dentition }\end{array}$ & $\begin{array}{l}\text { Permanent } \\
\text { dentition }\end{array}$ & $\begin{array}{l}\text { Mixed } \\
\text { dentition }\end{array}$ & $\begin{array}{l}\text { Permanent } \\
\text { dentition }\end{array}$ & & & & \\
\hline 0 & $14(32.5 \%)$ & $2(2.5 \%)$ & $4(2.2 \%)$ & $22(27.2 \%)$ & 185 (99.0\%) & 0 & $14(32.5 \%)$ & $7(8.6 \%)$ & $42(22.6 \%)$ \\
\hline 1 & $28(65.1 \%)$ & $23(28.4 \%)$ & 107 (57.5\%) & 49 (60.5\%) & $2(1.1 \%)$ & 1 & $19(44.1 \%)$ & $20(26.6 \%)$ & $66(35.5 \%)$ \\
\hline 2 & $7(16.2 \%)$ & - & - & $7(8.6 \%)$ & - & 2 & $17(39.3 \%)$ & - & $17(9.1 \%)$ \\
\hline 3 & - & - & $6(3.2 \%)$ & - & - & 3 & - & - & $3(1.6 \%)$ \\
\hline 4 & - & - & 64 (34.4\%) & $2(2.5 \%)$ & - & 4 & - & - & - \\
\hline 5 & $2(4.6 \%)$ & $1(1.2 \%)$ & $46(24.7 \%)$ & $7(8.7 \%)$ & - & 5 & $12(27.9 \%)$ & $4(4.9 \%)$ & $21(12.3 \%)$ \\
\hline 6 & - & - & - & $4(4.9 \%)$ & - & 6 & $5(11.6 \%)$ & $1(1.2 \%)$ & $57(30.6 \%)$ \\
\hline 7 & - & - & $1(0.5 \%)$ & - & - & 7 & - & - & 62 (33.3\%) \\
\hline 8 & - & 74 (91.4\%) & $133(71.5 \%)$ & - & - & 8 & - & $3(3.7 \%)$ & 105 (56.5\%) \\
\hline 9 & 41 (95.3\%) & 42 (51.9\%) & 143 (76.9\%) & $61(73.3 \%)$ & $1(0.5 \%)$ & 9 & - & $2(2.4 \%)$ & $4(2.1 \%)$ \\
\hline
\end{tabular}

a Code and criteria: 0: sound; 1: decay; 2: filled with decay; 3: filled with no decay; 4: missing due to caries; 5: missing due to other reason; 6: fissure sealant; 7: Bridge abutment, special crown; 8: unerupted tooth/crown, unexposed root; 9: not recorded

b Scores: 0: no treatment; 1: one surface filling; 2: two or more surface filling; 3: crown of any reasons; 4: veener and laminate; 5 : pulp care and restoration; 6 : extraction; 7: prosthesis; 8: oral prophylaxis; 9: not recorded

age group 35-44 years and 65-74 years were seen consuming alcohol, where most were consuming at least 2 drinks each time of consumption. Most part of Nepal has cold climatic condition. Alcohol has been socially and culturally accepted among many ethnic groups such as
Janajatis in Nepal. Population groups who do not belong to this ethnicity also have been found to be increasingly consuming alcohol [14].

The lesions observed on examination were very few cases of abscess, tobacco pouch keratosis, ulceration, and 
leukoplakia seen on the sulci, buccal mucosa, and floor of the mouth, and alveolar ridges. The most common lesion was tobacco pouch keratosis reflecting the high use of tobacco (70.0\%) among the study population. These findings were in accordance with the study done by Bansal et al. [19]. Oral mucosal lesions could be due to infection, local trauma, or irritation (keratosis, fibroma etc.), systemic diseases or related to lifestyle factors such as use of tobacco, areca nut or alcohol.

Teeth in good condition are fundamental for a healthy oral environment and the body as a whole. Missing teeth lead to compromised mastication, speech, and facial appearance that affect the overall physical and physiological status of an individual. It was seen that only four participants had prosthesis whereas about $25 \%$ needed prosthesis in the upper arch and 30\% needed prosthesis in the lower arch. Less use of prosthesis among the edentulous might be due to a lack of knowledge regarding the importance of the prosthesis and the poor socioeconomic status of the individuals. Similar kinds of findings were reported by the various studies [20-22].

About 3\% of the participants in the 35-44 years age group had healthy sextant. Sextant with pocket depth 4-5 $\mathrm{mm}$ was seen in $11.1 \%$ participants of age group $35-44$ years and $24.5 \%$ of age group $65-74$ years. Despite the high prevalence of brushing, sextant with calculus was most prevalent, with $82.3 \%$ in $35-44$ years age group and $74.5 \%$ in $65-74$ years age group. This might be due to irregular brushing practice and improper technique of brushing [23]. About $40 \%$ of the study populations were seen to be brushing 2-6 times per week. Loss of attachment of 4-5 mm was observed in 35-44 years age groups $(22.5 \%)$ and $4-5 \mathrm{~mm}$ in $65-74$ years age group (43.6\%) suggestive of periodontitis. The results were in accordance with the finding of the National Oral Health Pathfinder Survey where it was seen that $31 \%$ of the population belonging to the age group 35-44 years were having periodontitis [2]. Similar findings were also seen in the studies conducted by Goel et al. [24] and Varenne et al. [25]. The high tobacco consumption (70.6\%) in adult study participants might be the contributing to high prevalence of periodontal diseases among that study participants [26].

The study showed that $65.1 \%$ had decay in their primary dentition, $28.4 \%$ of decay was seen in mixed dentition, and $57.5 \%$ of tooth decay in permanent dentition, while recording for crown status. The prevalence of dental caries $(\mathrm{dft})$ in primary dentition was $65.1 \%$, which was similar to the finding by Bhagat et al. [8], and the prevalence of dental caries in participants with permanent dentition (DMFT) was $75.2 \%$. The mean dft was 2.40 and the mean DMFT was 3.18. The prevalence of dental caries was different than the National Oral Health Pathfinder
Survey 2004 where dental caries prevalence was reported as $58.0 \%$. The National Oral Health Pathfinder Survey was conducted more than a decade ago with an inclusive population of different ethnic communities whereas; these study participants mostly belonged to the underprivileged indigenous community. The neglected behavior of such a population towards oral health, irregular brushing and improper brushing technique leads to high caries and periodontal disease [27].

This study had some limitations. Since questions were asked about socioeconomic status, oral hygiene practice, discomfort/problems, probable chances of recall bias may have occurred because of the long time frame. Some of the respondents (27.1\%) were reluctant to give their income status so no responses were obtained even after multiple attempts. The study was conducted in Foklyan area and the finding cannot be generalized to the population of other areas. A larger survey is needed to explore further but this study can be considered as a reference for planning oral health programs for similar population.

\section{Conclusion}

This study concluded that most of the people of Foklyan area brush their teeth but not on a regular daily basis. There is a need for oral health promotion in this area that will enable them to better understand the importance of oral health. High prevalence of tobacco consumption among adult population and even half of the adolescent population already consuming tobacco products is an alarming issue. Appropriate tobacco control measure is must to control rampant tobacco use. Most of the study population belonged to the poor socioeconomic status; hence the financial burden of the oral diseases has added a detrimental effect on the individuals' health. This is the first study of its kind done to explore the oral health status targeting the under privileged indigenous community. Hence, this study gives an idea to the policy makers to focus on the preventive aspects to minimize the oral health burden of the marginalized.

\footnotetext{
Abbreviations

BPKIHS: B. P. Koirala Institute of Health Sciences; WHO: World Health Organization; DMFT: Decayed missing filled teeth; IRC: Institutional Review Committee; $\mathrm{Cl}$ : Confidence interval; TMJ: Temporomandibular joint; CPI: Community periodontal index; LOA: Loss of attachment.

Acknowledgements

We thank Dr. Santosh Kumari Agrawal, Dr. Ujwal Gautam and Mr. Raj Kumar Subedi for their help in formatting and editing the manuscript.

\section{Authors' contributions}

AS*, AS, and TKB conceived, conceptualized and designed the study. AS* collected and analyzed the data. DDB helped in analyzing the data. AS* drafted the manuscript and all co-authors read and contributed to the final manuscript, and agreed to its publication. (*Principal author). All authors read and approved the final manuscript.
} 


\section{Funding \\ None.}

\section{Availability of data and materials}

The data supporting the findings of this article are available from the corresponding author.

\section{Ethical approval and consent to participate}

Ethical approval was obtained from Institutional review committee, B. P. Koirala Institute of Health Sciences (BPKIHS), Dharan, Nepal (Committee's Ref. No: 300/074/074-IRC). The written informed consent was taken from the participants of 16 years or older and proxy consent was taken for individuals under 16 years. As the people under 16 years could not give written informed consent, it was mandatory for them to be accompanied by parents/guardians and the respective parents/ guardians signed the written informed consent for participants under 16 years.

\section{Consent for publication}

Data collection was anonymous. No images or other personal details of participants are presented here. The patients were informed about the details collected from them and consent was taken for the use of their details in a scientific publication.

\section{Competing interests}

The authors declare that they have no competing interests.

\section{Author details}

${ }^{1}$ Narayani Hospital, Birgunj, Parsa, Nepal. ${ }^{2}$ Department of Public Health Dentistry, B. P. Koirala Institute of Health Sciences, Dharan, Nepal. ${ }^{3}$ School of Public Health and Community Medicine, B. P. Koirala Institute of Health Sciences, Dharan, Nepal.

\section{Received: 30 July 2020 Accepted: 4 November 2020}

Published online: 11 November 2020

\section{References}

1. Grover HS, Bhardwaj A, Yadav N. Assessment of oral health status and periodontal treatment needs among rural, semi-urban, urban, and metropolitan population of Gurgaon District, Haryana State. J Indian Soc Periodontol. 2016;20(2):195.

2. Nepal OHP 2004. National Oral Health Policy (1), pp. 1-5.

3. Sharma A, Gaur A, Pareek S, Raja V, Sanadhya S, Sharma AB. Oral health status and treatment needs among orphanage children of Jaipur City. Sch J App Med Sci. 2014;2(5D):1776-80.

4. Dixit LP, Shakya A, Shrestha M, Shrestha A. Dental caries prevalence, oral health knowledge and practice among indigenous Chepang school children of Nepal. BMC Oral Health. 2013;13(1):20.

5. Kamran A, Bakhteyar K, Heydari H, Lotfi A, Heydari Z. Survey of oral hygiene behaviors, knowledge and attitude among school children: a cross-sectional study from Iran. Int J Health Sci. 2014;2(2):95-83.

6. Vaidya AK, Pokharel PK, Nagesh S, Karki P, Kumar S, Majhi S. Association of obesity and physical activity in adult males of Dharan. Nepal Kathmandu Univ Med J (KUMJ). 2005;4(14):192-7.

7. Sampaio FC, Freitas CH, Cabral MB, Machado AT. Dental caries and treatment needs among indigenous people of the Potiguara Indian reservation in Brazil. Revista Panamericana de Salud Pública. 2010;27:246-51.

8. Bhagat TK, Shrestha A. Prevalence of dental caries among public school children in the Eastern Nepal. J Chitwan Med Coll. 2014;4(1):30-2.

9. World Health Organization. Oral health surveys: basic methods. Geneva: World Health Organization; 1997.
10. World Health Organization. Oral health surveys: basic methods. Geneva: World Health Organization; 2013.

11. Ghosh A, Ghosh T. Modification of Kuppuswamy's socioeconomic status scale in context to Nepal. Indian Pediatr. 2009;46(12):1104-5.

12. Nepal Rastra Bank. Recent Macroeconomic and financial Situation. Research department, Statistics Division, Kathmandu, Nepal. https://nrb. org.np/ofg/current.../CME\%20Nine\%20Months\%20Tables\%202073-74. xIsx. Accessed 21 Nov 2017.

13. Bennet L, Dahal DR, Govindasamy P. Caste, ethnic and regional identity in Nepal: further analysis of the 2006 Demographic and Health Surveys. Calverton: Macro International Inc.; 2008.

14. Thapa P, Aryal KK, Mehata S, Vaidya A, Jha BK, Dhimal M, Pradhan S, Dhakal P, Pandit A, Pandey AR, Bista B. Oral hygiene practices and their socio-demographic correlates among Nepalese adult: evidence from non communicable diseases risk factors STEPS survey Nepal 2013. BMC Oral Health. 2016;16(1):105.

15. Handa S, Prasad S, Rajashekharappa CB, Garg A, Ryana HK, Khurana C. Oral health status of rural and urban population of Gurgaon block, Gurgaon district using $\mathrm{WHO}$ assessment form through multistage sampling technique. J Clin Diagn Res. 2016;10(5):ZC43.

16. Gambhir RS, Sogi GM, Veeresha KL, Sohi RK, Randhawa A, Kakar H. Dental health status and treatment needs of transport workers of a northern Indian city: A cross-sectional study. J Nat Sci Biol Med. 2013;4(2):451.

17. Nimako-Boateng J, Owusu-Antwi M, Nortey P. Factors affecting dental diseases presenting at the University of Ghana Hospital. SpringerPlus. 2016;5(1):1709.

18. Omitola $\mathrm{OG}$, Arigbede AO. Prevalence and pattern of pain presentation among patients attending a tertiary dental center in a southern region of Nigeria. J Dent Res Dent Clin Dent Prospects. 2010;4(2):42.

19. Bansal V, Sogi GM, Veeresha KL, Kumar A, Bansal S. Dentition status and treatment needs of prisoners of Haryana state, India. Int J Prison Health. 2012;8(1):27-34.

20. Tramini P, Montal S, Valcarcel J. Tooth loss and associated factors in long-term institutionalised elderly patients. Gerodontology. 2007;24(4):196-203.

21. Carter G, Lee M, McKelvey V, Sourial A, Halliwell R, Livingston M. Oral health status and oral treatment needs of dependent elderly people in Christchurch. N Z Med J. 2004;117(1194):892.

22. Peltola P, Vehkalahti MM, Wuolijoki-Saaristo K. Oral health and treatment needs of the long-term hospitalised elderly. Gerodontology. 2004;21(2):93-9.

23. Lertpimonchai A, Rattanasiri S, Arj-Ong Vallibhakara S, Attia J, Thakkinstian A. The association between oral hygiene and periodontitis: a systematic review and meta-analysis. Int Dent J. 2017;67(6):332-43.

24. Goel P, Singh K, Kaur A, Verma M. Oral healthcare for elderly: Identifying the needs and feasible strategies for service provision. Indian J Dent Res. 2006;17(1):11.

25. Varenne B, Petersen PE, Ouattara S. Oral health status of children and adults in urban and rural areas of Burkina Faso, Africa. Int Dent J. 2004;54(2):83-9.

26. Bergström J. Tobacco smoking and chronic destructive periodontal disease. Odontology. 2004;92(1):1-8.

27. John JR, Daniel B, Paneerselvam D, Rajendran G. Prevalence of dental caries, oral hygiene knowledge, status, and practices among visually impaired individuals in Chennai, Tamil Nadu. Int J Dent. 2017;2017:9419648

\section{Publisher's Note}

Springer Nature remains neutral with regard to jurisdictional claims in published maps and institutional affiliations. 